\title{
Metal-Organic Frameworks for Metal-Ion Batteries: Towards Scalability
}

\author{
Semyon Bachinin, Venera Gilemkhanova, Maria Timofeeva, \\ Yuliya Kenzhebayeva, Andrei Yankin * (D), Valentin A. Milichko * \\ School of Physics and Engineering, ITMO University, 197101, St. Petersburg, Russia \\ * Corresponding authors: andrei.yankin@metalab.ifmo.ru, v.milichko@metalab.ifmo.ru \\ This article belongs to the regular issue. \\ (C) 2021, The Authors. This article is published in open access form under the terms and conditions of the Creative \\ Commons Attribution (CC BY) license (http://creativecommons.org/licenses/by/4.0/).
}

\begin{abstract}
Metal-organic frameworks (MOFs), being a family of highly crystalline and porous materials, have attracted particular attention in material science due to their unprecedented chemical and structural tunability. Next to their application in gas adsorption, separation, and storage, MOFs also can be utilized for energy transfer and storage in batteries and supercapacitors. Based on recent studies, this review describes the latest developments about MOFs as structural elements of metal-ion battery with a focus on their industry-oriented and large-scale production.
\end{abstract}

\section{Keywords}

metal-organic frameworks

batteries

spin coating

vapour deposition

Received: 30.07 .2021

Revised: 23.08.2021

Accepted: 25.08.2021

Available online: 27.08 .2021

\section{Introduction}

Global energy consumption is growing every year, which is associated with active social and economic development. However, limited natural energy resources and climatic changes, caused by their extraction and use, call into question the previous pace of development. In this sense, the development of new green technologies that ensure the energy storage in batteries and energy transfer in an environmentally friendly way is becoming more relevant than ever. Global industrial auto giants such as Mercedes also support such transition to green energy. Despite unprecedented successes in the development of such batteries and accumulators, chemical and physical limitations of existing (organic, inorganic and hybrid) materials yet hinder the wide commercial application and require new solutions in material science. For instance, limited life of the batteries and their cycle stability, physical and chemical stability of structural elements, limited charge/discharge rates, capacity, as well as recyclability of the batteries [1] are cornerstones of the future technology of the clean energy. In this sense, metal-organic frameworks (MOFs) can be considered as new attractive candidates to meet the requirements of next-generation energy storage devices [2].

Emerged over 20 years ago [3], MOFs have become one of the key materials in chemistry and crystal engineering. Being as a family of highly crystalline and porous materials, MOFs are composed of metal nodes and organic ligands linked by coordination bonds. Their "LEGO" nature possesses an unlimited structural and compositional versatility, providing the desired chemical and physical properties [4]. Due to synthetic design, MOFs' properties such as crystal structure, porosity, stability, and conductivity can be tailored for specific applications. Therefore, such synthetic versatility of MOFs allows one to optimize the functional properties for energy storage [5], since the needs of each device are different.

Today, MOFs, depending on their designed properties, are utilized as the main structural elements of the batteries (Fig. 1): electrodes, solid-state electrolyte, separator and potentially contacts with the metallic conductivity [610]. There are many reviews covering the design [5,11-16] fabrication, operation, limitations, and prospects of specific MOFs as individual structural elements such as cathodes and anodes [17-26], electrolytes and separators [27-30]. However, the problem associated with the creation of scalable MOFs for mass (as BASF, MOF-WORX, and NuMat make [31-34]) and large-scale production with focus on energy applications has not been addressed. Here we discuss the latest developments about MOFs as structural elements of metal-ion battery focusing on their industryoriented production by thin film technology: spin coating and recently developed chemical vapour deposition.

\section{Discussion}

Generally, metal-ion batteries are composed of three major components: anode and cathode with different chemical potentials, immersed in an ion-conducting and electri- 


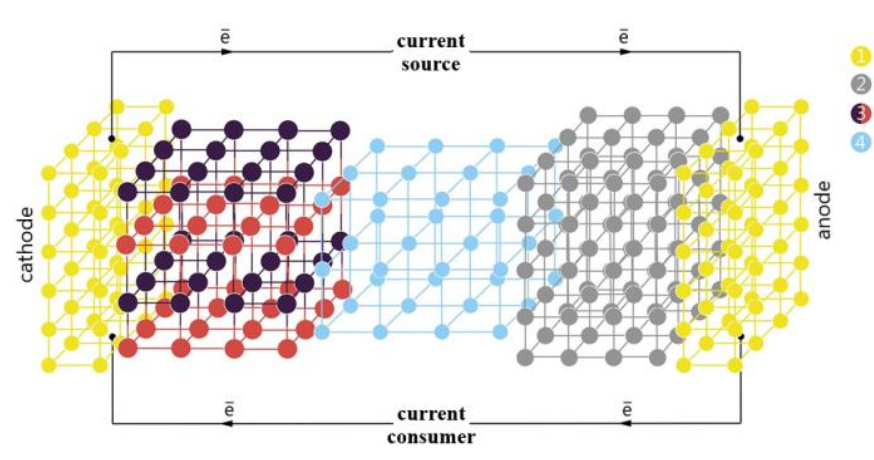

Fig. 1 Schematic illustration of MOFs (porous coordination polymers) as solid-state electrolytes (4), cathode (3) and anode (2) coating as well as potential electronic conductors (1)

cally insulating electrolyte (Fig. 1). The electrochemical reactions in such batteries are the following: metal ion diffusion within the electrode, charge transfer at the interface between the electrodes and electrolyte, and metal ion transport through the electrolyte. Herein, the recharging of the batteries (i.e. current source) occurs in a "rockingchair" fashion: metal ions transfer between cathode and anode during charge/discharge cycles (Fig. 1). During discharge (i.e. current consumer), metal ions travel from the anode to the cathode, while electrons move externally from the anode to the cathode.

Metal-organic frameworks demonstrate high potential to optimize the performance of metal-ion batteries. This is facilitated by a number of their distinctive properties such as porosity, redox behavior, various types of conductivity (ionic and electronic), encapsulation of various molecules and ions, etc. Fig. 1 demonstrates a schematic diagram of a metal ion battery with highlighted areas corresponding to MOFs as cathodes, anodes, solid-state electrolytes and separators.

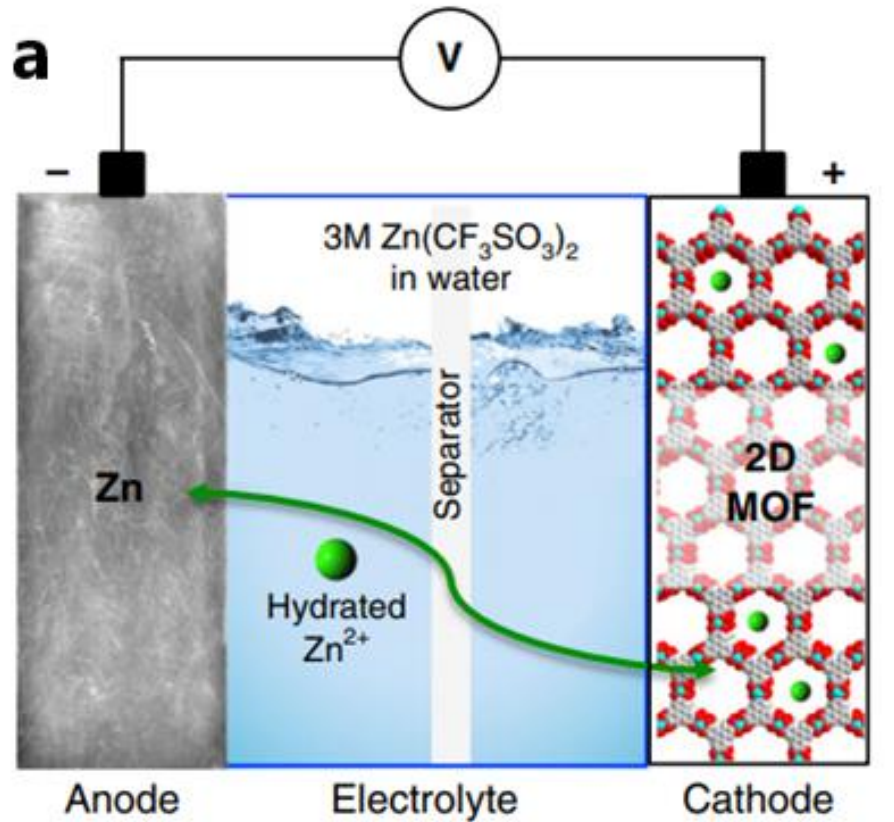

First, we consider MOFs as cathodes and anodes. Generally, metal-organic frameworks are semiconductors in nature, in some cases the band gap reaches up to $5 \mathrm{eV}$. Nevertheless, there are compounds with the lower band gap possessing hopping electronic conductivity. The mechanisms of electronic transport in MOFs are the following [35-37]: through-bond, through-plane, through-space, redox-hopping, and guest-promoted pathways. This provides an opportunity to utilize $\mathrm{ZIF}-8\left(\mathrm{Zn}(\mathrm{mIm})_{2}\right.$, where $\mathrm{mIm}=$ 2-methylimidazolate), metal-ion batteries, addressing two issues: providing electron transport and insertion/extraction of ions due to redox activity [38-40]. Nam et al. [38] were able to combine these two properties and provide a prototype of the metal-ion battery with a cathode entirely made of two-dimensional MOF $\left(\mathrm{Cu}_{3}(\mathrm{HHTP})_{2}\right.$, where HHTP - 2,3,6,7,10,11hexahydroxytriphenylene) with an electronic conductivity of $0.2 \mathrm{~S} \mathrm{~cm}^{-1}$ (Fig. 2a). Also, Li et al. [40] demonstrated similar approach, but for the anode (Fig. 2b).

Deposition of metal-organic frameworks on the anodes also allows one to improve the capacitive characteristics of metal-ion batteries due to insertion/extraction of various ions through the MOF layer. This makes it possible to increase the effective anode area without changing the dimensional characteristics of the device, which, in its turn, promises miniaturization of existing batteries. A number of papers [41-48], considering such an approach, demonstrate the achievement of significant results in current densities, charge capacity, and cyclic stability. The mechanism of insertion/extraction of ions is also described in details in [44] using the example of aluminumbased MOF (Fig. 3). In addition, the deposition of MOFs on the cathodes possesses the similar effect, which has been considered by the authors of [48-52].
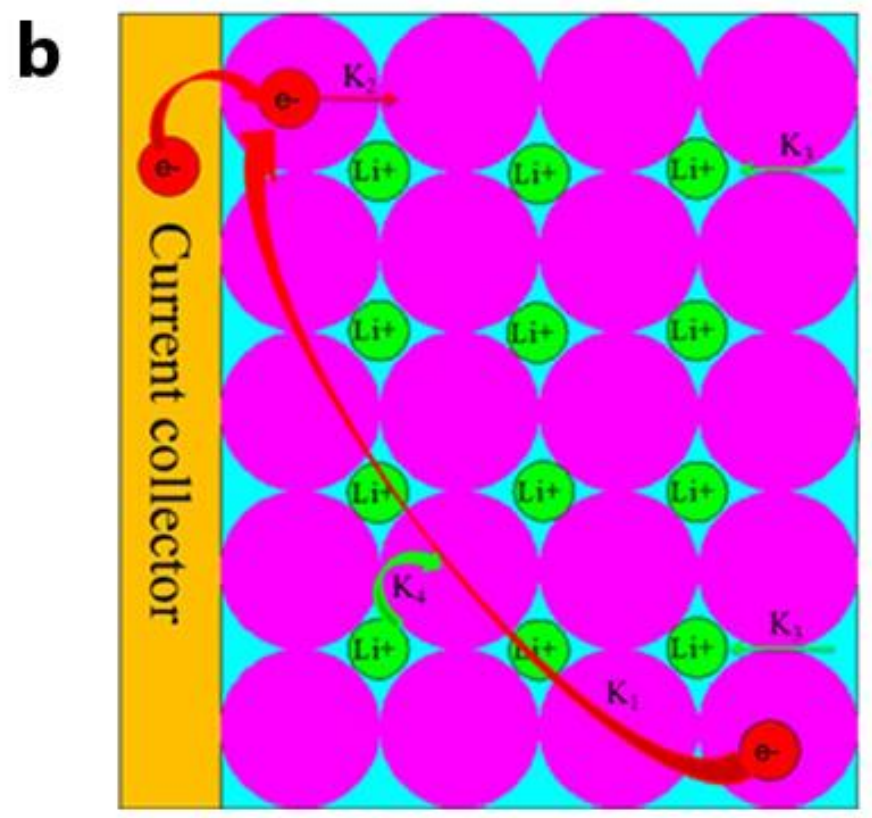

Fig. 2 The concept for the MOF as a cathode (a) [38] and anode (b) [40] 


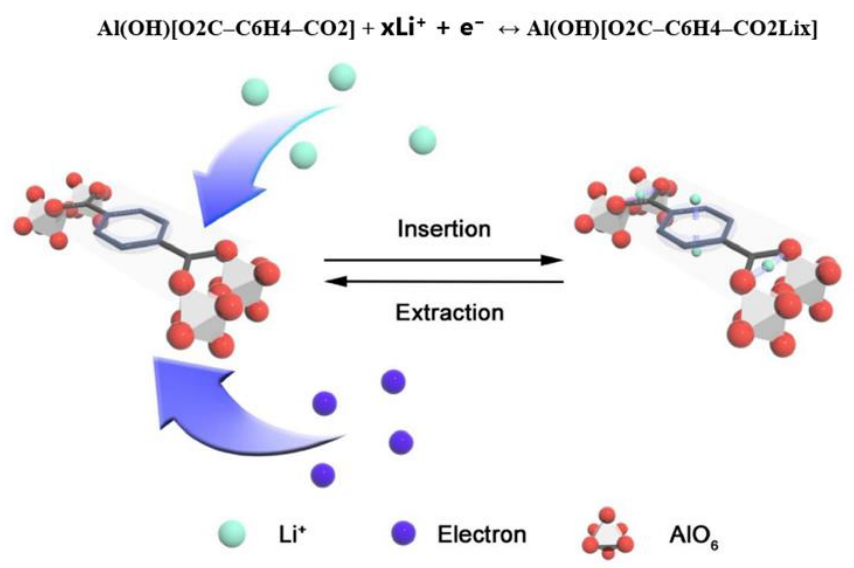

Fig. 3 The mechanism of insertion/extraction of various ions through MOF layer [44]

Utilization of metal-organic frameworks as an active medium for ion transport is the other side of the story. The porous structure provides ion transport through the MOF, which allows one to consider it as a solid-state electrolyte [53-59]. The reason to use MOF as a solid-state electrolyte is dictated, first, by a decrease in the toxicity of the resulting metal-ion batteries. Indeed, the common liquid electrolytes are extremely toxic, which makes the process of disposal quite difficult and expensive. Such toxicity also makes existing batteries extremely unsafe for use in electronic devices for children. In this sense, the transition from the liquid electrolytes towards solid-state ones can improve this issue and allows the batteries to be recyclable. In addition, a number of metal-organic frameworks demonstrate promising operation characteristics under the extreme conditions: high temperatures, mechanical stress, directed thermal action, etc. A number of recent research works [54-59] prove the validity of this suggestions through the embedding of metal-organic frameworks as an additional layer [58] (Fig. 4c) or making the energy device based on MOF as an active layer [57] (Fig. 4a,b). Also, a review of potentially suitable compositions of MOFs as solid-state electrolytes can be found in [59].

The increasing focus on industrially applicable MOFs [31-34] for microelectronics and energy applications highlight significant limitations of common solution methods and emphasizes the need for more scalable technologies like Roll-on approach, which is highly needed for production of portable batteries. The possibility of the scaling of the synthesis of functional MOFs is directly related to the development of technologies for the growth of highquality crystals in the form of thin films. To address this issue, first, we consider spin coating approach [6o-64]. This is one of the simplest methods for MOF scalability allowing the deposition of MOF films on different rigid and flexible substrates (metal, semiconductor or dielectric) with different morphologies. The method consists of the interaction of droplets of two solutions (an organic ligand and a metal salt) on the surface of a rotating substrate (Fig. 5a) [6o]. Due to the high rotation speeds of the substrate, the resulting film has relatively good uniformity in thickness and composition (Fig. 5b).

The heating of the substrate can be also applied to increase both the rate of synthesis and the crystallinity. The authors of [61] obtained a $150 \mathrm{~nm}$ film on an aluminum electrode at a rotation speed of $3000 \mathrm{rpm}$ and a substrate temperature of $140{ }^{\circ} \mathrm{C}$, which can potentially a

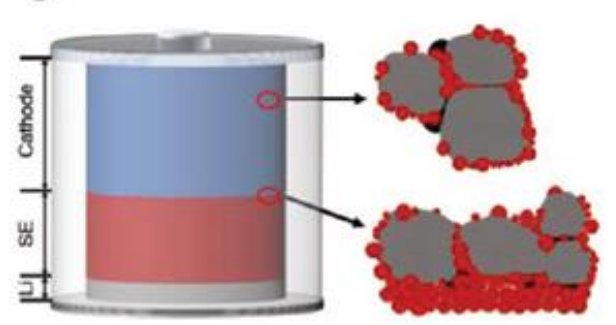

b

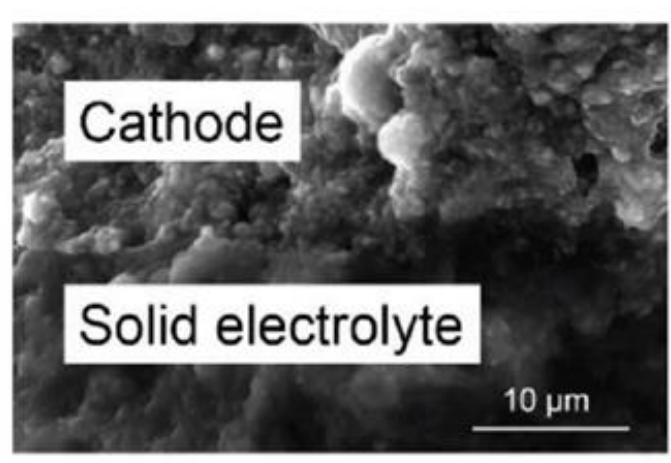

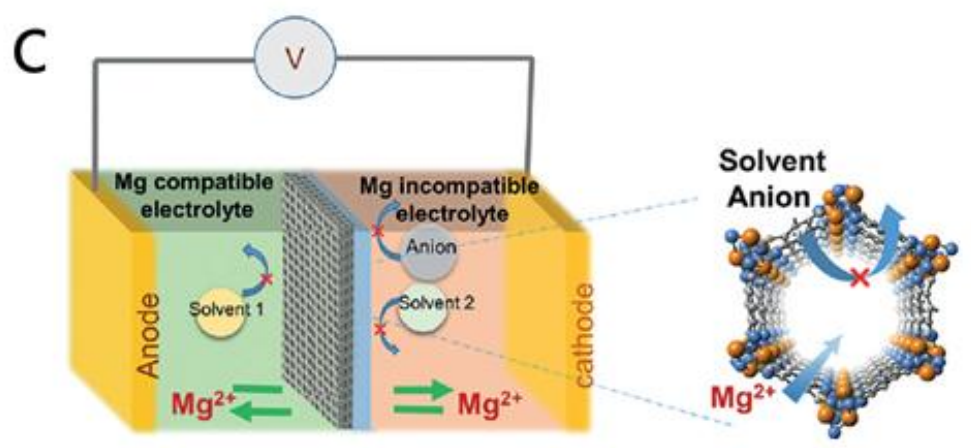

Fig. 4 MOF as a solid-state electrolyte (a,b) [57] and separator film (c) [58] 
a)

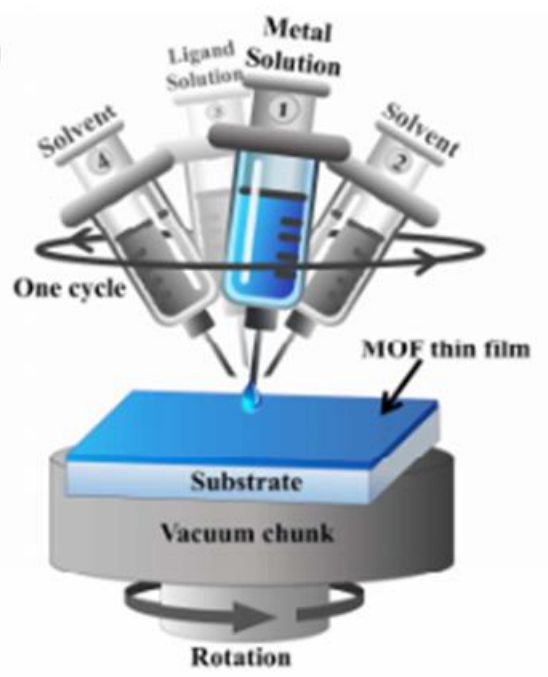

b)

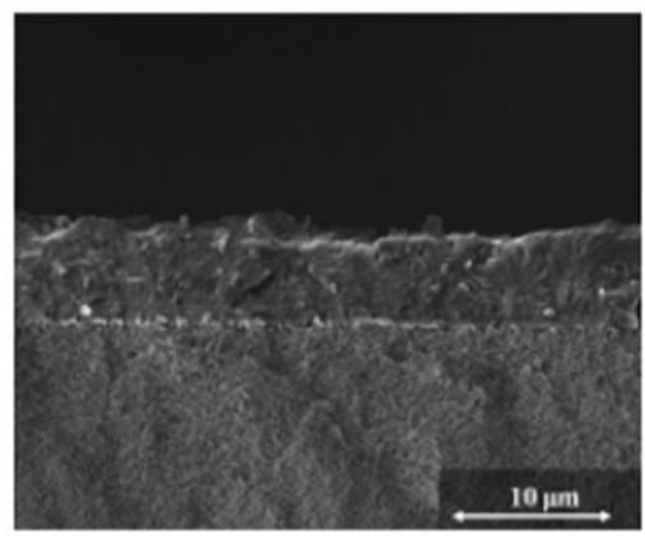

Fig. 5 Schematic illustration of spin-coating approach (a) and cross-section view of MOF thin film obtained by scanning electron microscopy (b) [6o]

be used for the process of modifying the electrodes of metal-ion batteries. Chen et al. [62] also showed the possibility of spin-coating the flexible film with an electronic type of conductivity, which is interesting as electrode layers in the device of metal-ion batteries. Also, direct evidence of the validity of the spin-coating technology application follows from the paper [63] where Fan et al. modified the surface of the Zn-MOF anode by centrifugation. Finally, considering the battery, whose structure consists of multilayer MOFs as electrodes, electrolytes and separators (Fig. 1), the specific technology is required. In this sense, the spin-coating makes it possible to fabricate such multilayer structures, as evidenced by the results obtained in [64].

Next highly promising approach is chemical vapour deposition (CVD) [65-74]. Indeed, CVD as a non-solvent method is a well-known industrial approach for obtaining surfaces suitable for micro- and optoelectronics since the corrosion and contamination issues are solved. A variant of CVD, MOCVD (metal-organic CVD) is a standard process for laser diode, LED, and semiconductor manufacturing, meaning it can be used for MOF synthesis, as well. Following the research works on MOF CVD, common structures such as ZIF-8, ZIF-67 $\left(\mathrm{Co}(\mathrm{mIm})_{2}\right.$, where $\mathrm{mIm}=$ 2-methylimidazolate), HKUST-1 $\left(\mathrm{Cu}_{3}(\mathrm{BTC})_{2}\right.$, where BTC $=$ benzene-1,3,5-tricarboxylic acid) and MIL-53 (Al-BDC, where $\mathrm{BDC}=1,4$ benzene dicarboxylic acid), recently utilized for energy storage [21], can be prepared as model thin films. However, in contrast to solution chemistry, the limited possibilities of CVD for using a variable concentration of various solvents significantly limit the resulting MOF topologies, while it is not an insurmountable problem for the method.

The general concept of MOF CVD is illustrated in Fig. 6. Rob Ameloot and co-workers describe this methods as a two-step procedure [65]: the deposition of the metal oxide layer on a support by, for instance, atomic layer deposition (ALD), followed by the exposure of this oxide coating

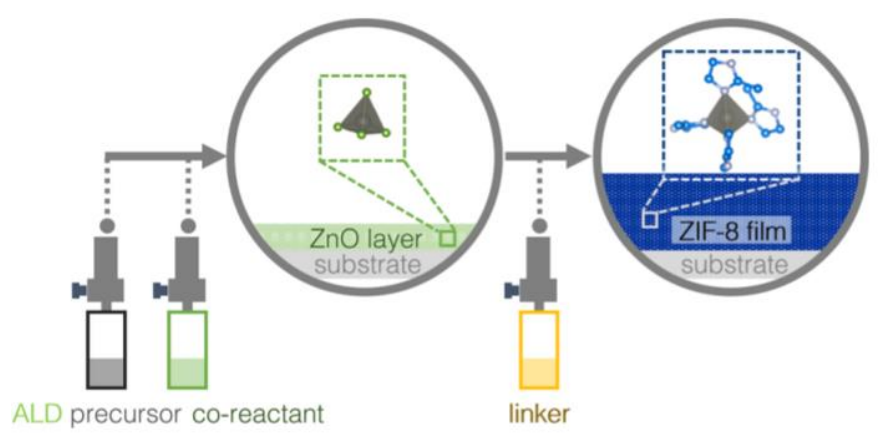

Fig. 6 Schematic illustration of MOF CVD process [68]

to a vaporized linker resulting in a vapor-solid reaction towards the formation of the desired MOF structures. Following this approach, ZIF-8 films were obtained by Stassen et al. [65]. ZIF-8 was deposited on silicon pillars with a 25:1 aspect ratio by vapour-solid transformation of 25 nm ALD zinc oxide films. It is vital to mention the possibility of obtaining conformal coatings by such approach on various, often fragile, surfaces. Intriguing, the presence of water during synthesis promotes formation of a nonporous diamondoid $\mathrm{Zn}(\mathrm{mIM})_{2}$ polymorph, but under high temperatures the water evaporation eliminates the chances of amorphous material to form.

Similar effect of lack of solvent has been demonstrated by Han et al. [66] who reported solvent-free HKUST-1 film deposition under vacuum conditions. They combined CVD and physical vapour deposition processes using layer-bylayer (LBL) growth where after each $\mathrm{H}_{3} \mathrm{BTC}$ deposition cycle a monolayer $\mathrm{Cu}$ was grown again.

The group of Ameloot [67] also reported the growth of MOF based on $\mathrm{Cu}(\mathrm{II})$ and linkers 1,4-benzenedicarboxylic acid $\left(\mathrm{H}_{2} \mathrm{BDC}\right)$ and trans-1,4-cyclohexanedicarboxylic acid $\left(\mathrm{H}_{2} \mathrm{CDC}\right)$. The MOF-CVD method for these materials consists of two steps: vapour-phase deposition of copper or copper oxide films as a metal source, and a solid-vapour reaction between this precursor and the vaporised organic linker. It is important to note that depending on synthesis 
conditions (dry or humid) diverse MOFs' structures were obtained. For $\mathrm{H}_{2} \mathrm{CDC}$ linker humidity did not play a major role and porous CuCDC was normally formed. However, for $\mathrm{H}_{2} \mathrm{BDC}$ linker, depending on the humidity level, CuBDC or $\mathrm{CP}-\mathrm{CuBDC}$ structure similar to coordination polymer $\left[\mathrm{Cu}_{2}(\mathrm{OH})_{2}(\mathrm{BDC})\right]$ could be obtained.

A number of emerging problems in the process of MOFCVD, such as the incomplete conversion of the metal-oxide precursor to MOF, and the degradation of the organic ligand during deposition at elevated temperature were described [68-71]. A possible solution was proposed by Cruz et al. [68]: involving an increase of exposure time and decrease of the thickness of the metal-oxide precursor. Furthermore, the use of low-temperature synthesis $\left(80^{\circ} \mathrm{C}\right.$ ) conditions to circumvent these challenges was explored for MAF-6 (RHO-Zn(eIm $)_{2}$, where eIm = 2-ethylimidazolate) [69], MAF-252 (Zn(dpt $)_{2}$, where dpt $=3$-(2-pyridyl)-5-(4-pyridyl)-1,2,4-triazolate) $\quad$ [70] (Fig. 7), ZIF-8 and ZIF-67 [71] structures.

Another issue comes from MOF-CVD method itself that allows obtaining MOFs with limited porosity [65-71]. This deteriorates a whole range of functional properties including ion transport. This issue can be overcome by accounting for the following factors $[67,68]$ : (i) humidity has to be controlled since it can increase chances of amorphous intermediate formation, thus, affecting thin film roughness - the more humid conditions are, the rougher are the films produced; (ii) the thickness of metal-oxide precursor has to be controlled in order to fully convert it into MOF. Otherwise, it acts as a protecting shell that hampers further MOF growth. So far, only model MOFs with relatively simple topologies and short ligands have been synthesized by CVD, therefore, leaving room for further investigations of MOFs with more complex hierarchy and variable ion/electron conductivity.

The report by Stassin et al. [72] creates a basis for the direct comparison of the solvothermal and vapour deposition methods for the synthesis of functional and polymorphic MOFs. MOFs Al-MIL-53-Fum and Al-MIL-53-Mes (AlMIL-68-Mes) were synthesized with and without modulators. When formic acid was used as a modulator, MOF crystallized at $80{ }^{\circ} \mathrm{C}$ by CVD in the orthorhombic crystal system with Pnma space group. At the same time, modula-
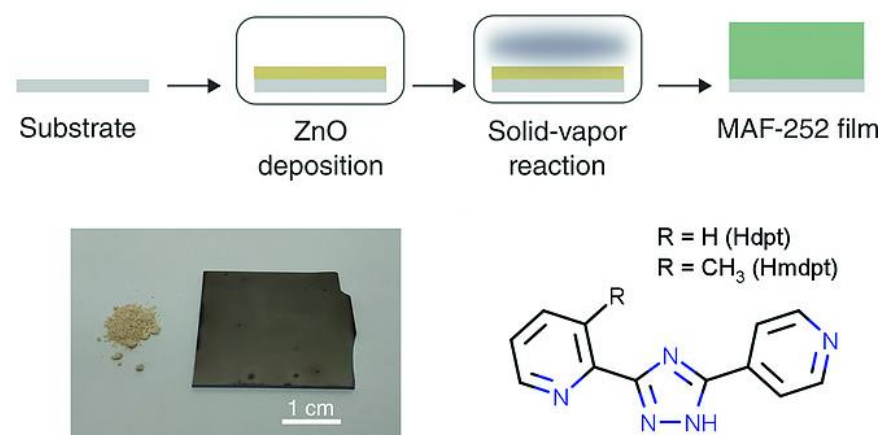

Fig. 7 The scheme of MAF-252 thin film fabrication with corresponding optical images of MAF-252 powder and large-scale film [70] tor-free product crystallized by solvothermal method in the monoclinic space group $P 21 / C$. The change of the modulator from formic to mesaconic acid led to formation of Al-MIL-53-Mes by CVD that crystallizes in the orthorhombic with Pnma space group. This work highlighted the principle possibility of the controlled synthesis of structurally diverse compounds via conscious vapour deposition synthesis.

Similar message was conveyed by a very recent work by $\mathrm{Tu}$ et al. [73], which described another approach to controlled MOF-CVD synthesis by using the so-called template vapor that arranges the MOF building blocks and promotes the formation of desired product. They found out that the reaction between zinc oxide and 4,5-dichloroimidazole (HdcIm) leads to the formation of either porous kinetic phase ZIF-71 [Zn(dcim)2] $(\mathrm{dcim}=$ 4,5-dichloroimidazolate) with RHO topology, or thermodynamically stable phase ZIF-72 (the same chemical formula as ZIF-71) with LCS topology. The addition of template vapors enabled formation of ZIF-71 at lower temperatures $\left(120{ }^{\circ} \mathrm{C}\right.$ vs $\left.160{ }^{\circ} \mathrm{C}\right)$; however, at temperatures above $120^{\circ} \mathrm{C}$ it was impossible to avoid the phase transition from ZIF-71 to ZIF-72.

\section{Conclusions}

Conventional solution chemistry certainly remain the key approach for the synthesis of MOFs for diverse applications including electrochemical energy storage [74]. However, the increasing focus on industrially applicable MOFs [31-34] for microelectronics, optics [75] and energy application highlight significant limitations of the solution methods and emphasizes the need for more scalable and industry-oriented technologies. Here, we cover advanced methods, such as spin coating and vapour deposition techniques, allowing large-scale and fast productions of functional MOFs. These industrially oriented and scalable methods demonstrate high potential for producing the functional MOF thin films. Specifically, the CVD technique appears as the most optimal and promising method for the industrial manufacture of MOFs. The intense research during the past 5 years identified a number of technological challenges hampering the implementation of MOF-CVD and indicated avenues for their solution. The key challenges include the incomplete conversion of the metal-oxide precursor to MOF, the degradation of the organic ligand during deposition at elevated temperature [68-71], as well as growth of MOFs with limited porosity [65-71]. All these issues can potentially be addressed. Also, over the past year, the possibility of large-scale growth of MOFs with a structural diversity has been also demonstrated [73,74], which, we believe, will be one of the driving forces in MOF crystal engineering in the near future.

Concerning spin coating approach, there are still technological problems of MOF thin film fabrication such as a poorly controlled growth process, the influence of external 
factors (mechanical vibrations, convection flows and insufficient automation), and a limited list of structural elements (especially ligands) involved in the crystal growth. The latter is associated with the high growth rate of thin films during the spin coating, which does not allow sufficiently large ligands (porphyrins, TBAPY etc.) to organize a porous periodic lattice. Finally, inhomogeneity of the film (domain structure) and a high degree of surface roughness limit the applicability of the method.

In our review, we also omitted the other industrially oriented methods for scalable MOF fabrication, such as electrochemistry, mechanochemistry and microwaveassisted synthesis. The reason for this is the rather high degree of development of these methods, which is reflected in the relevant reviews [76-81].

\section{Acknowledgments}

The authors acknowledge the financial support from the Russian Foundation for Basic Research (Project No. 20-1350454).

\section{References}

1. Nguyen TP, Easley AD, Kang N, Khan S, Lim SM, Rezenom YH, Wooley KL. Polypeptide organic radical batteries. Nature. 2021;593(7857):61-6.

doi:10.1038/s41586-021-03399-1

2. Xu G, Nie P, Dou H, Ding B, Li L, Zhang X. Exploring metal organic frameworks for energy storage in batteries and supercapacitors. Materials Today. 2017;20(4):191-209. doi:10.1016/j.mattod.2016.10.003

3. Li H, Eddaoudi M, O'Keeffe M, Yaghi OM. Design and synthesis of an exceptionally stable and highly porous metalorganic framework.

Nature. 1999;402(6759):276-79. doi:10.1038/46248

4. Mezenov YA, Krasilin AA, Dzyuba VP, Nominé A, Milichko VA. Metal-organic frameworks in modern physics: Highlights and perspectives. Advanced Science. 2019;6(17):1900506. doi:10.1002/advs.201900506

5. Baumann AE, Burns DA, Liu B, Thoi VS. Metal-organic framework functionalization and design strategies for advanced electrochemical energy storage devices. Communications Chemistry. 2019;2(1):1-14. doi:10.1038/s42004-0190184-6

6. Xie LS, Skorupskii G, Dincă M. Electrically conductive metalorganic frameworks.

Chemical reviews. 2020;120(16):8536-80.

doi:10.1021/acs.chemrev.9boo766

7. Dou JH, Sun L, Ge Y, Li W, Hendon CH, Li J, Dincă M. Signature of metallic behavior in the metal-organic frameworks M3 (hexaiminobenzene) $2(\mathrm{M}=\mathrm{Ni}, \mathrm{Cu})$. Journal of the American Chemical Society. 2017;139(39):136o8-11. doi:10.1021/jacs.7bo7234

8. Clough AJ, Orchanian NM, Skelton JM, Neer AJ, Howard SA, Downes CA, Marinescu SC. Room Temperature Metallic Conductivity in a Metal-Organic Framework Induced by Oxidation. Journal of the American Chemical Society. 2019;141(41):16323-30. doi:10.1021/jacs.9bo6898

9. He Y, Cubuk ED, Allendorf MD, Reed EJ. Metallic metalorganic frameworks predicted by the combination of machine learning methods and ab initio calculations. The journal of physical chemistry letters. 2018;9(16):4562-9. doi:10.1021/acs.jpclett.8b01707
10. Foster ME, Sohlberg K, Allendorf MD, Talin AA. Unraveling the semiconducting/metallic discrepancy in Ni3 (HITP) 2. The journal of physical chemistry letters. 2018;9(3):481-6. doi:10.1021/acs.jpclett.7b03140

11. Zhong M, Kong L, Zhao K, Zhang YH, Li N, Bu XH. Recent Progress of Nanoscale Metal-Organic Frameworks in Synthesis and Battery Applications. Advanced Science. 2021;8(4):2001980. doi:10.1002/advs.202001980

12. Zheng ZJ, Ye H, Guo ZP. Recent progress on pristine metal/covalent-organic frameworks and their composites for lithium-sulfur batteries. Energy \& Environmental Science. 2021;14(4):1835-53. doi:10.1039/DoEE03181J

13. Thakur AK, Majumder M, Patole SP, Zaghib K, Reddy MV. Metal-organic framework-based materials: advances, exploits, and challenges in promoting post Li-ion battery technologies. Materials Advances. 2021;2(8):2457-82. doi:10.1039/DoMA01019G

14. Wen X, Zhang Q, Guan J. Applications of metal-organic framework-derived materials in fuel cells and metal-air batteries. Coordination Chemistry Reviews. 2020;409:213214. doi:10.1016/j.ccr.2020.213214

15. Sun W, Tang X, Wang Y. Multi-metal-organic frameworks and their derived materials for Li/Na-ion batteries. Electrochemical Energy Reviews. 2020;3(1):127-54. doi:10.1007/s41918-019-00056-0

16. Mehtab T, Yasin G, Arif M, Shakeel M, Korai RM, Nadeem M, Lu X. Metal-organic frameworks for energy storage devices: batteries and supercapacitors. Journal of Energy Storage. 2019;21:632-46. doi:10.1016/j.est.2018.12.025

17. Du J, Li F, Sun L. Metal-organic frameworks and their derivatives as electrocatalysts for the oxygen evolution reaction. Chemical Society Reviews. 2021;4461(4):214118. doi:10.1039/DoCSO1191F

18. Yan R, Ma T, Cheng M, Tao X, Yang Z, Ran F, Yang W. MetalOrganic-Framework-Derived Nanostructures as Multifaceted Electrodes in Metal-Sulfur Batteries. Advanced Materials. 2021;33(27):2008784. doi:10.1002/adma.202008784

19. Zhu W, Li A, Wang Z, Yang J, Xu Y. Metal-Organic Frameworks and Their Derivatives: Designing Principles and Advances toward Advanced Cathode Materials for Alkali Metal Ion Batteries. Small. 2021;17(22):2006424. doi:10.1002/smll.202006424

20. Jiang Y, Zhao H, Yue L, Liang J, Li T, Liu Q, Sun X. Recent advances in lithium-based batteries using metal organic frameworks as electrode materials.

Electrochemistry Communications. 2020;22:106881. doi:10.1016/j.elecom.2020.106881

21. Zhao R, Liang Z, Zou R, Xu Q. Metal-organic frameworks for batteries. Joule. 2018;2(11):2235-59. doi:10.1016/j.joule.2018.09.019

22. Reddy RCK, Lin J, Chen Y, Zeng C, Lin X, Cai Y, Su CY. Progress of nanostructured metal oxides derived from metalorganic frameworks as anode materials for lithium-ion batteries. Coordination Chemistry Reviews. 2020;420:213434. doi:10.1016/j.ccr.2020.213434

23. Wu Q, Zhou X, Xu J, Cao F, Li C. Carbon-based derivatives from metal-organic frameworks as cathode hosts for $\mathrm{Li}-\mathrm{S}$ batteries. Journal of Energy Chemistry. 2019;38:94-113. doi:10.1016/j.jechem.2019.01.005

24. Wang ZY, Tao HZ, Yue Y. Metal-organic-framework-based cathodes for enhancing the electrochemical performances of batteries: a review. ChemElectroChem. 2019;6(21):5358-74. doi:10.1002/celc.201900843

25. Shrivastav V, Sundriyal S, Goel P, Kaur H, Tuteja SK, Vikrant K, Deep A. Metal-organic frameworks (MOFs) and their composites as electrodes for lithium battery applications: Novel means for alternative energy storage. Coordination Chemistry Reviews. 2019;393:48-78. doi:10.1016/j.ccr.2019.05.006 
26. Zhang L, Liu H, Shi W, Cheng P. Synthesis strategies and potential applications of metal-organic frameworks for electrode materials for rechargeable lithium ion batteries. Coordination Chemistry Reviews. 2019;388:293-309. doi:10.1016/j.ccr.2019.02.030

27. Barbosa J, Gonçalves RF, Costa CM, de Zea Bermudez V, Fidalgo A, Zhang Q, Lanceros-Mendez S. Metal-organic frameworks and zeolite materials as active fillers for lithium-ion battery solid polymer electrolytes. Materials Advances. 2021;2(12):3790-805. doi:10.1039/D1MAo0244A

28. Huang WH, Li XM, Yang XF, Zhang XX, Wang HH, Wang $\mathrm{H}$. The recent progress and perspectives on metal-and covalentorganic framework based solid-state electrolytes for lithiumion batteries. Materials Chemistry Frontiers. 2021;5(9):3593-613. doi:10.1039/DoQMoo936A

29. Chu Z, Gao X, Wang C, Wang T, Wang G. Metal-organic frameworks as separators and electrolytes for lithium-sulfur batteries. Journal of Materials Chemistry A. 2021;9(12):7301-16. doi:10.1039/DoTA11624F

3o. Chen T, Chen S, Chen Y, Zhao M, Losic D, Zhang S. Metalorganic frameworks containing solid-state electrolytes for lithium metal batteries and beyond. Materials Chemistry Frontiers. 2021;5(4):1771-94. doi:10.1039/doqmoo856g

31. Furukawa H, Müller U, Yaghi OM. "Heterogeneity within order" in metal-organic frameworks. Angewandte Chemie International Edition. 2015;54(11):3417-30. doi:10.1002/anie.201410252

32. Ren J, Dyosiba X, Musyoka NM, Langmi HW,Mathe M. Review on the current practices and efforts towards pilot-scale production of metal-organic frameworks (MOFs). Coordination Chemistry Reviews. 2017;352:187-219. doi:10.1016/j.ccr.2017.09.005

33. Silva P, Vilela SMF, Tome JPC, Almeida Paz FA. Multifunctional metal-organic frameworks: from academia to industrial applications. Chemistry Society Reviews. 2015;44:6774803. doi:10.1039/c5cs00307e

34. Rubio-Martinez M, Avci-Camur C, Thornton AW, Imaz I, Maspoch D, Hill MR. New synthetic routes towards MOF production at scale. Chemical Society Reviews. 2017;46(11):3453-80. doi:10.1039/c7cs00109f

35. Johnson EM, Ilic S, Morris AJ. Design Strategies for Enhanced Conductivity in Metal-Organic Frameworks. ACS Central Science.2021;7(3):445-53. doi:10.1021/acscentsci.1c00047

36. Liu J, Song X, Zhang T, Liu S, Wen H, Chen L. 2D Conductive Metal-Organic Frameworks: An Emerging Platform for Electrochemical Energy Storage. Angewandte Chemie International Edition. 2021;6o(11):5612-24. doi:10.1002/anie.202006102

37. Day RW, Bediako DK, Rezaee M, Parent LR, Skorupskii G, Arguilla MQ, Dincă M. Single crystals of electrically conductive two-dimensional metal-organic frameworks: Structural and electrical transport properties. ACS central science. 2019;5(12):1959-64. doi:10.1021/acscentsci.9bo1006

38. Nam KW, Park SS, dos Reis R. et al. Conductive 2D metalorganic framework for high-performance cathodes in aqueous rechargeable zinc batteries. Nature Community. 2019;10:4948. doi:10.1038/s41467-019-12857-4

39. Gu S, Bai Z, Majumder S, Huang B, Chen G. Conductive metal-organic framework with redox metal center as cathode for high rate performance lithium ion battery. Journal of Power Sources. 2019;429:22-9. doi:10.1016/j.jpowsour.2019.04.087

40. Li Z, Huang X, Sun C, Chen X, Hu J, Stein A, Tang B. Thin-film electrode based on zeolitic imidazolate frameworks (ZIF-8 and ZIF-67) with ultra-stable performance as a lithium-ion battery anode. Journal of Materials Science. 2017;52:3979-91. doi:10.1007/s10853-016-0660-7

41. Luo Y, Wu M, Pang B, Ge J, Li R, Zhang P, Okada S. Metal-organic Framework of [Cu2 (BIPA-TC)(DMA) 2] n: A Promising Anode Material for Lithium-Ion Battery. ChemistrySelect. 2020;5(14):4160-4. doi:10.1002/slct.202000503
42. Weng YG, Yin WY, Jiang M, Hou JL, Shao J, Zhu QY, Dai J. Tetrathiafulvalene-Based Metal-Organic Framework as a High-Performance Anode for Lithium-Ion Batteries. ACS Applied Materials \& Interfaces. 2020;12(47):52615-23. doi:10.1021/acsami.oc14510

43. Han Y, Qi P, Zhou J, Feng X, Li S, Fu X, Wang B. Metal-organic frameworks (Mofs) as sandwich coating cushion for silicon anode in lithium ion batteries. ACS applied materials \& interfaces. 2015;7(48):266o8-13. doi:10.1021/acsami.5bo8109

44. Gao C, Wang P, Wang Z, Kær SK, Zhang Y, Yue Y. The disordering-enhanced performances of the AlMOF/graphene composite anodes for lithium ion batteries. Nano Energy. 2019;65:104032. doi:10.1016/j.nanoen.2019.104032

45. Zhao G, Tang L, Zhang L, Chen X, Mao Y, Sun K. Well-developed capacitive-capacity of metal-organic framework derived $\mathrm{Co}_{3} \mathrm{O}_{4}$ films in Li ion battery anodes. Journal of Alloys and Compounds. 2018;746:277-84. doi:10.1016/j.jallcom.2018.02.285

46. Mutahir S, Wang C, Song J, Wang L, Lei W, Jiao X, Hao Q. Pristine Co (BDC) TEDo. 5 a pillared-layer biligand cobalt based metal organic framework as improved anode material for lithium-ion batteries. Applied Materials Today. 2020;21:100813. doi:10.1016/j.apmt.2020.100813

47. Wang J, Dong S, Zhang Y, Chen Z, Jiang S, Wu L, Zhang X. Metal-organic framework derived titanium-based anode materials for lithium ion batteries.

Nano-Structures \& Nano-Objects. 2018;15:48-53. doi:10.1016/j.nanoso.2018.03.004

48. Li H, Lang J, Lei S, Chen J, Wang K, Liu L, Yan X. A High-Performance Sodium-Ion Hybrid Capacitor Constructed by Metal-Organic Framework-Derived Anode and Cathode Materials. Advanced Functional Materials. 2018;28(30):1800757. doi:10.1002/adfm.201800757

49. Nagarathinam M, Saravanan K, Phua EJH, Reddy MV, Chowdari BVR, Vittal JJ. Redox-Active Metal-Centered Oxalato Phosphate Open Framework Cathode Materials for Lithium Ion Batteries.

Angewandte Chemie International Edition. 2012;51(24):5866-70. doi:10.1002/anie.201200210

50. Zou F, Liu K, Cheng CF, Ji Y, Zhu, Y. Metal-organic frameworks (MOFs) derived carbon-coated NiS nanoparticles anchored on graphene layers for highperformance Li-S cathode material. Nanotechnology. 2020;31(48):485404. doi:10.1088/1361-6528/abaegb

51. Xue R, Liu N, Bao L, Chen L, Su Y, Lu Y, Wu F. UiO-66 type metal-organic framework as a multifunctional additive to enhance the interfacial stability of Ni-rich layered cathode material. Journal of Energy Chemistry. 2020;50:378-86. doi:10.1016/j.jechem.2020.03.049

52. Shimizu T, Wang H, Matsumura D, Mitsuhara K, Ohta T, Yoshikawa H. Porous Metal-Organic Frameworks Containing Reversible Disulfide Linkages as Cathode Materials for Lithium-Ion Batteries. ChemSusChem. 2020;13(9):2256-22. doi: $10.1002 /$ cssc. 201903471

53. Sadakiyo M, Kitagawa H. Ion-conductive metal-organic frameworks. Dalton Transactions. 2021;50(16):5385-97. doi:10.1039/DoDT04384B

54. Wiers BM, Foo ML, Balsara NP, Long JR. A solid lithium electrolyte via addition of lithium isopropoxide to a metal-organic framework with open metal sites. Journal of the American Chemical Society. 2011;133(37):14522-5. doi:10.1021/ja205827Z

55. Fujie K, Ikeda R, Otsubo K, Yamada T, Kitagawa H. Lithium ion diffusion in a metal-organic framework mediated by an ionic liquid. Chemistry of Materials. 2015;27(21):7355-61. doi:10.1021/acs.chemmater.5bo2986 
56. Park SS, Tulchinsky Y, Dincă M. Single-ion $\mathrm{Li}^{+}, \mathrm{Na}^{+}$, and $\mathrm{Mg}^{2+}$ solid electrolytes supported by a mesoporous anionic $\mathrm{Cu}-$ azolate metal-organic framework.

Journal of the American Chemical Society. 2017;139(38):1326o-3. doi:10.1021/jacs.7bo6197

57. Wu JF, Guo X. Nanostructured Metal-Organic Framework (MOF)-Derived Solid Electrolytes Realizing Fast Lithium Ion Transportation Kinetics in Solid-State Batteries. Small. 2019;15(5):1804413. doi:10.1002/smll.201804413

58. Luo J, Li Y, Zhang H, Wang A, Lo WS, Dong Q, Wang D. A metal-organic framework thin film for selective $\mathrm{Mg}^{2+}$ transport. Angewandte Chemie International Edition. 2019;58(43):15313-17. doi:10.1002/anie.201908706

59. Kinik FP, Uzun A, Keskin S. Ionic liquid/metal-organic framework composites: from synthesis to applications. ChemSusChem. 2017;10(14):2842-63. doi:10.1002/cssc.201700716

6o. Chernikova V, Shekhah O, Eddaoudi M. Advanced fabrication method for the preparation of MOF thin films: Liquid-phase epitaxy approach meets spin coating method. ACS applied materials \& interfaces. 2016;8(31):20459-64. doi:10.1021/acsami.6bo4701

61. Gutierrez M, Martín C, Souza BE, Van der Auweraer M, Hofkens J, Tan JC. Highly luminescent silver-based MOFs: Scalable eco-friendly synthesis paving the way for photonics sensors and electroluminescent devices.

Applied Materials Today. 2020;21:100817. doi:10.1016/j.apmt.2020.100817

62. Chen X, Lu Y, Dong J, Ma L, Yi Z, Wang Y, Liu Y. Ultrafast In Situ Synthesis of Large-Area Conductive MetalOrganic Frameworks on Substrates for Flexible Chemiresistive Sensing. ACS Applied Materials \& Interfaces. 2020;12(51):57235-44. doi:10.1021/acsami.0c18422

63. Fan L, Guo Z, Zhang Y, Wu X, Zhao C, Sun X, Zhang N. Stable artificial solid electrolyte interphase films for lithium metal anode via metal-organic frameworks cemented by polyvinyl alcohol. Journal of Materials Chemistry A. 2020;8(1):251-8. doi:10.1039/c9ta10405d

64. Gutierrez M, Martín C, Souza BE, Van der Auweraer M, Hofkens J, Tan JC. Highly luminescent silver-based MOFs: Scalable eco-friendly synthesis paving the way for photonics sensors and electroluminescent devices. Applied Materials Today. 2020;21:100817. doi:10.1016/j.apmt.2020.100817

65. Stassen I, Styles M, Grenci G, Van Gorp H, Vanderlinden W, De Feyter S, Ameloot R. Chemical vapour deposition of zeolitic imidazolate framework thin films. Nature materials. 2016;15(3):304-10. doi:10.1038/nmat4509

66. Han S, Ciufo RA, Meyerson ML, Keitz BK, Mullins CB. Solvent-free vacuum growth of oriented HKUST-1 thin films. Journal of Materials Chemistry A. 2019;7(33):19396-406. doi:10.1039/c9ta05179a

67. Stassin T, Rodríguez-Hermida S, Schrode B, Cruz AJ, Carraro F, Kravchenko D, Ameloot R. Vapour-phase deposition of oriented copper dicarboxylate metal-organic framework thin films. Chemical Communications. 2019;55(68):10056-9. doi:10.1039/c9cc05161a

68. Cruz AJ, Stassen I, Krishtab M, Marcoen K, Stassin T, Rodríguez-Hermida S, Teyssandier J, Pletincx S, Verbeke R, Rubio-Giménez V. Integrated Cleanroom Process for the Vapor-Phase Deposition of Large-Area Zeolitic Imidazolate Framework Thin Films. Chem Mater. 2019;31:9462. doi:10.1021/acs.chemmater.9bo3435
69. Stassin T, Stassen I, Marreiros J, Cruz AJ, Verbeke R, Tu M, Reinsch H, Dickmann M, Egger W, Vankelecom IFJ. Solvent-Free Powder Synthesis and MOF-CVD Thin Films of the Large-Pore Metal-Organic Framework MAF-6. Chem Mater. 2020;32:1784. doi:10.1021/acs.chemmater.9bo3807

70. Stassin T, Stassen I, Wauteraerts N, Cruz AJ, Kräuter M, Coclite AM, de Vos D, Ameloot R. Solvent-Free Powder Synthesis and Thin Film Chemical Vapor Deposition of a Zinc Bipyridyl-Triazolate Framework. Eur J Inorg Chem. 2020;2020:71. doi:10.1002/ejic.201901051

71. Krishtab M, Stassen I, Stassin T, Cruz AJ, Okudur OO, Armini S, Wilson C, de Gendt S, Ameloot R. Vapor-deposited zeolitic imidazolate frameworks as gap-filling ultra-low-k dielectrics. Nature Communications. 2019;10:3729. doi:10.1038/s41467-019-11703-X

72. Stassin T, Waitschat S, Heidenreich N, Reinsch H, Pluschkell F, Kravchenko D, Marreiros J, Stassen I, van Dinter J, Verbeke R. Aqueous Flow Reactor and Vapour-Assisted Synthesis of Aluminium Dicarboxylate Metal-Organic Frameworks with Tuneable Water Sorption Properties. Chemistry. 2020;26:10841. doi:10.1002/chem.202001661

73. Tu M, Kravchenko DE, Xia B, Rubio-Giménez V, Wauteraerts N, Verbeke R, Vankelecom IFJ, Stassin T, Egger W, Dickmann M. Template-mediated control over polymorphism in the vapor-assisted formation of zeolitic imidazolate framework powders and films. Angew Chem Int Ed. 2021;133:7631. doi:10.1002/anie.202014791

74. Stock N, Biswas S. Synthesis of metal-organic frameworks (MOFs): routes to various MOF topologies, morphologies, and composites. Chemical reviews. 2012;112(2):933-69. doi:10.1021/cr200304e

75. Mezenov YA, Kulachenkov NK, Yankin AN, Rzhevskiy SS, Alekseevskiy PV, Gilemkhanova VD, Milichko VA. Polymer Matrix Incorporated with ZIF-8 for Application in Nonlinear Optics. Nanomaterials. 2020;10(6):1036. doi: $10.3390 /$ nano10061036

76. Isaeva VI, Kustov LM. Microwave activation as an alternative production of metal-organic frameworks. Russian Chemical Bulletin. 2016;65(9):2103-14. doi:10.1007/s11172-016-1559-9

77. Thomas-Hillman I, Laybourn A, Dodds C, Kingman SW. Realising the environmental benefits of metal-organic frameworks: recent advances in microwave synthesis. Journal of Materials Chemistry A. 2018;6(25):11564-81. doi:10.1039/c8ta02919a

78. Khan NA, Jhung SH. Synthesis of metal-organic frameworks (MOFs) with microwave or ultrasound: Rapid reaction, phase-selectivity, and size reduction. Coord Chem Rev. 2015;285:11-23. doi:10.1016/j.ccr.2014.10.008

79. Głowniak S, Szczęśniak B, Choma J, Jaroniec M. Mechanochemistry: Toward green synthesis of metal-organic frameworks. Materials Today. 2021;46:109-24. doi:10.1016/j.mattod.2021.01.008

8o. Al-Kutubi H, Gascon J, Sudhölter EJR, Rassaei L. Electrosynthesis of Metal-Organic Frameworks: Challenges and Opportunities. ChemElectroChem. 2015;2(4):462-74. doi:10.1002/celc.201402429

81. Liu J, Woll C. Surface-supported metal-organic framework thin films: Fabrication methods, applications, and challenges. Chem Soc Rev. 2017;46:5730-70. doi:10.1039/C7CSo0315C 